2015-04

\title{
Serotonin stimulates secretion of exosomes from microglia cells
}

\author{
Glebov, Konstantin
}

http://hdl.handle.net/10026.1/13242

10.1002/glia.22772

Glia

Wiley

All content in PEARL is protected by copyright law. Author manuscripts are made available in accordance with publisher policies. Please cite only the published version using the details provided on the item record or document. In the absence of an open licence (e.g. Creative Commons), permissions for further reuse of content should be sought from the publisher or author. 


\title{
Serotonin Stimulates Secretion of Exosomes from Microglia Cells
}

\author{
Konstantin Glebov, ${ }^{1}$ Marie Löchner, ${ }^{1}$ Ronald Jabs, ${ }^{2}$ Thorsten Lau, ${ }^{3}$ Olaf Merkel, ${ }^{1}$ \\ Patrick Schloss, ${ }^{3}$ Christian Steinhäuser, ${ }^{2}$ and Jochen Walter ${ }^{1}$
}

\begin{abstract}
Microglia are resident immune cells in the brain and exert important functions in the regulation of inflammatory processes during infection or cellular damage. Upon activation, microglia undergo complex morphological and functional transitions, including increased motility, phagocytosis and cytokine secretion. Recent findings indicate that exosomes, small vesicles that derive from fusion of multivesicular bodies with the plasma membrane, are involved in secretion of certain cytokines. The presence of specific receptors on the surface of microglia suggests communication with neurons by neurotransmitters. Here, we demonstrate expression of serotonin receptors, including $5-\mathrm{HT}_{2 a, b}$ and $5-\mathrm{HT}_{4}$ in microglial cells and their functional involvement in the modulation of exosome release by serotonin. Our data demonstrate the involvement of cAMP and Ca ${ }^{2+}$ dependent signaling pathways in the regulation of exosome secretion. Co-culture of microglia with embryonic stem cellderived serotonergic neurons further demonstrated functional signaling between neurons and microglia. Together, these data provide evidence for neurotransmitter-dependent signaling pathways in microglial cells that regulate exosome release.
\end{abstract}

Key words: insulin-degrading enzyme, neuron-glia interaction, unconventional secretory pathway

GLIA 2015;63:626-634

\section{Introduction}

$\mathrm{M}$ icroglia are brain immune cells and serve important functions in the innate immune response, including phagocytosis and cytokine release upon infection and cell damage (for review: Kettenmann et al., 2011). Microglia are highly dynamic cells and constantly screen the brain for threats. Upon stimulation, microglia undergo complex physiological and morphological transitions from "resting state" with a highly ramified cell body to a mobile 'activated state' (for review: Kettenmann et al.; 2011Streit, 2002). Along with the alterations in cell morphology and motility, microglia also change the expression of various cell surface molecules, release of chemokines and cytokines, and increase phagocytic activity.

Recent findings indicate that certain cytokines are released in association with small vesicles named exosomes (Bianco et al., 2005). These microglia-derived vesicles could play important roles in the inflammatory response and neurotransmission (for review: Prada et al., 2013; Turola et al., 2012). A variety of proteins could be found in the lumen and limiting membranes of exosomes (for review: Simpson et al., 2009). Exosomes can transfer different molecules between cells including proteins, lipids and RNAs, and mediate secretion of cellular waste into extracellular fluids (for review: van Niel et al., 2006).

Exosomes are formed intracellularly by inward budding of endosomal membranes to generate multivesicular bodies (MVBs). After fusion of MVBs with the plasma membrane, the intraluminal vesicles are released as exosomes (Simons and Raposo, 2009). Exosomes are found in different body fluids like blood, urine, and cerebrospinal fluid (Keller et al., 2011; Street et al., 2012). However, very little is known about the extracellular stimuli and downstream signaling pathways that regulate exosome secretion.

View this article online at wileyonlinelibrary.com. DOI: 10.1002/glia.22772

This article was published online on 1 December 2014. An error was subsequently identified. This notice is included in the online and print versions to indicate that both have been corrected on 18 December 2014.

Published online December 1, 2014 in Wiley Online Library (wileyonlinelibrary.com). Received June 4, 2014, Accepted for publication Nov $13,2014$.

Address correspondence to Jochen Walter, Department of Neurology, University of Bonn, Bonn, Germany. E-mail: Jochen.Walter@ukb.uni-bonn.de

From the ${ }^{1}$ Department of Neurology, University of Bonn, Bonn, Germany; ${ }^{2}$ Institute of Cellular Neurosciences, Medical School, University of Bonn, Bonn, Germany; ${ }^{3}$ Biochemical Laboratory, Central Institute of Mental Health, Medical Faculty Mannheim, University Heidelberg, Heidelberg, Germany

Author contributions: JW and KG conceived the project, designed experiments and wrote the manuscript; RJ and CS performed calcium measurements; KG, ML, and $\mathrm{OM}$ performed secretion experiments and exosome preparations; OM made the gene expression analysis. TL, KG, and ML performed the co-culture assay. All authors edited and approved the manuscript. 
The presence of neurotransmitter receptors on microglia surface suggests that microglia could receive signals from neurons (for review: Pocock and Kettenmann, 2007). 5-HT receptors (5HTRs) have been described on microglia, but their functional relevance remains unclear (Krabbe et al., 2012). Some of the 5HTRs belong to the G-protein coupled receptor superfamily and regulate two major signaling pathways. One group of 5-HTRs

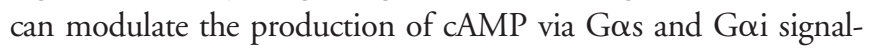
ing to adenylate cyclase (AC). The second group regulates phospholipiase C (PLC) via G $\alpha \mathrm{q}$ (for review: Berumen et al., 2012). 5-HT has multiple functions such as regulation of sleep and digestion and is also involved in pathophysiological conditions like irritable bowel syndrome and schizophrenia (MohammadZadeh et al., 2008).

In this study we demonstrate that 5-HT can stimulate release of exosomes from microglial cells via activation of 5$\mathrm{HT}_{2 \mathrm{a}, \mathrm{b}}$ and $5-\mathrm{HT}_{4}$ receptors. Further, embryonic stem cellderived serotonergic neurons could trigger exosome release from microglia in a co-culture system, indicating that release of serotonin from neurons could regulate microglial release of exososmes under physiological conditions. $\mathrm{Ca}^{2+}$ imaging revealed an elevation of cytosolic $\mathrm{Ca}^{2+}$ levels in microglia upon stimulation with 5-HT. Together, our data indicate that 5-HT from neurons can signal to microglia via 5-HTRs to stimulate exosome release.

\section{Materials and Methods \\ Cell Culture}

Murine microglial BV-2 cells were cultured in Dulbecco's modified Eagle's medium (DMEM) supplemented with $10 \%$ fetal calf serum (PAN) and $1 \%$ penicillin and streptomycin (v/v) (Life Technologies). Cells were grown on 10-cm dishes (Greiner) or T-75 flasks (Corning). Cells were incubated at $37^{\circ} \mathrm{C}$ with $5 \% \mathrm{CO}_{2}$ atmosphere till confluence of $70-80 \%$. Pharmacological treatments were carried out in 24-well plates (Corning) with $8 \times 10^{4}$ cells per well. Upon treatment, medium was replaced by serum-free DMEM containing $1 \%$ penicillin and streptomycin (v/v).

Primary microglia were derived from embryonic 18 (e18) mouse brains (C57BL/6J). Hippocampi were isolated and trypsinyzed. Dissected material was incubated with Trypsin 0.1\%/EDTA for $13 \mathrm{~min}$, separated by passing through a glass pipette and plated onto T-75 flasks in RPMI (Life Technologies) with L-glutamine, $10 \%$ FBS (PAN), and 1\% Penicillin/Streptomycin (Life Technologies). After fourteen days in vitro, microglia were removed by shaking at $100 \mathrm{rpm}$ for $2 \mathrm{~h}$. Conditioned medium was replaced by fresh one and mixed culture was incubated for another week. Harvest was repeated as described above.

\section{Antibodies}

The following antibodies were used: polyclonal rabbit antibody against the insulin degrading enzyme (IDE) (Abcam, ab25970), mouse monoclonal antibodies against $\beta$-actin (SIGMA, a1978) and flotillin-1 (BD sciences, 610820). Primary antibodies were detected by horse radish peroxidaseconjugated anti-rabbit and anti-mouse secondary antibodies (SIGMA, a9169 and a9044).

\section{Chemicals}

Serotonin creatinine sulfate monohydrate $(25 \mu \mathrm{M}$, Carl Roth, 8385.1), GR113808 (100 nM, Tocris, 1322), altanserine hydrochloride (10 nM, Tocris, 1809), RS127445 hydrochloride $(5 \mu \mathrm{M}$, Tocris, 2993), m-3m3FBS (5 $\mu \mathrm{M}$ for $5 \mathrm{~h}$, Tocris, 1941), U73122 $(5 \mu \mathrm{M}$, Tocris, 1268), 8CPT-2Me-cAMP (8 $\mu \mathrm{M}$, Tocris, 1645), thapsigargin (1 $\mu \mathrm{M}$ for $3 \mathrm{~h}$, Invitrogen, T-7458) and pertussis toxin (500 $\mathrm{ng}$ $\mathrm{mL}^{-1}$, Invitrogen, PHZ1174). All compounds were dissolved in DMSO.

\section{Secretion Assay and Immunoblot Analysis}

Cells were treated with the respective compounds for $16 \mathrm{~h}$ as described in the figure legends. Where indicated, cells were preincubated with receptor antagonists for $6 \mathrm{~h}$. Conditioned media were collected and centrifuged $\left(1,000 g, 10 \mathrm{~min}, 4^{\circ} \mathrm{C}\right)$. Proteins were precipitated with trichloroacetic acid $(20 \%, w / v)$ and sodium deoxycholate $(0.02 \% \mathrm{w} / \mathrm{v}$; Calbiochem) on ice, sedimented by centrifugation $\left(16,000 \mathrm{~g}, 10 \mathrm{~min}, 4^{\circ} \mathrm{C}\right)$, and resulting pellets dissolved in Tris-SDS buffer $(0.25 \%$ bromophenol blue, $0.5 \mathrm{M}$ dithiothreitol, $50 \%$ glycerol, $10 \%$ sodium dodecyl sulfate, $0.25 \mathrm{M}$, pH 6.8Tris-Cl). Cells were lysed in ice-cold RIPA lysis buffer ( $\mathrm{pH}$ 7.5). Proteins were separated by sodium dodecyl sulfate-polyacrylamide gel electrophoresis (SDS-PAGE), transferred to nitrocellulose membranes (Whatman), and detected by Western immunoblotting using enhanced chemiluminescence imaging (ChemiDoc XRS, Bio-Rad). Signals were quantified with Quantity One Software (Bio-Rad).

\section{Exosome Preparation}

Exosomes in conditioned media were isolated via differential centrifugation as described earlier (Tamboli et al., 2010a). Briefly, media were centrifuged for $10 \mathrm{~min}$ at $300 \mathrm{~g}$, twice for $10 \mathrm{~min}$ at $2,000 \mathrm{~g}$, then $30 \mathrm{~min}$ at $10,000 \mathrm{~g}$ and finally for $1 \mathrm{~h}$ at $100,000 \mathrm{~g}$. The respective supernatants and pellets were analyzed by Western immunoblotting.

\section{RNA Isolation and RT-PCR Analysis}

Total RNA was extracted from BV-2 cells using the RNeasy Mini Kit (Qiagen) according to the manufacturer's instructions. RNA was reverse-transcribed with the SuperScript ${ }^{\circledR}$ III First-Strand Synthesis System (life Technologies) using random hexamers primers according to the manufacturer's instructions. Two- $\mu \mathrm{L}$ aliquots of cDNA were subjected to PCR using 10x PCR buffer without $\mathrm{Mg}^{2+}, 50 \mathrm{mM}$ $\mathrm{MgCl}_{2}, 10 \mathrm{mM}$ dNTP mix, $100 \mathrm{pM}$ of each primer and Taq DNA polymerase. DEPC-treated water was added to a final volume of 50 $\mu \mathrm{L}$. PCR was performed for 35 cycles $\left(30 \mathrm{~s}\right.$ at $95^{\circ} \mathrm{C}, 30 \mathrm{~s}$ at $65^{\circ} \mathrm{C}$ and $2 \mathrm{~min}$ at $72^{\circ} \mathrm{C}$ ), preceded by a denaturation step at $95^{\circ} \mathrm{C}$ for 4 min and terminated with an elongation step at $70^{\circ} \mathrm{C}$ for $5 \mathrm{~min}$. PCR products were analyzed on $1.5 \%$ agarose gels containing 
A

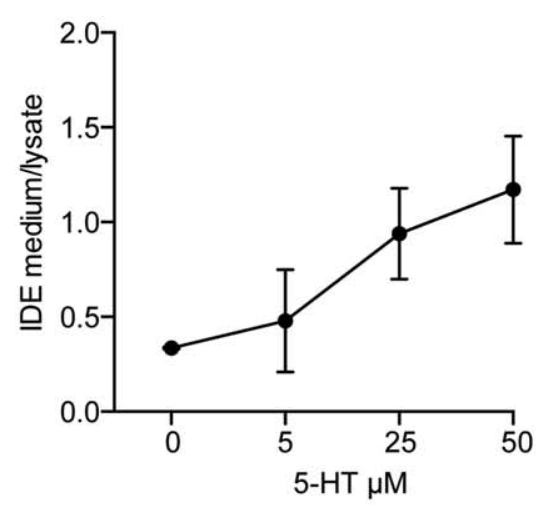

B

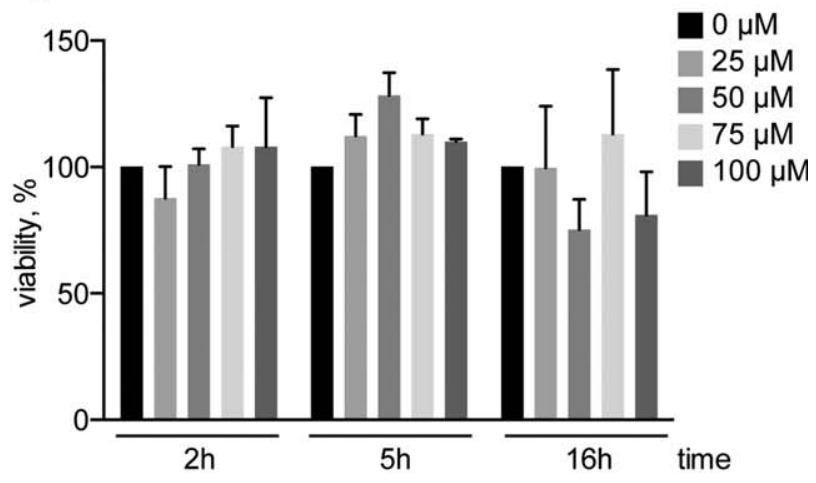

D

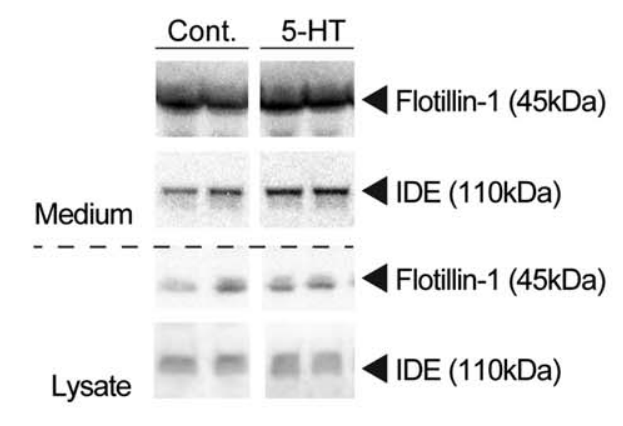

Flotillin-1

IDE

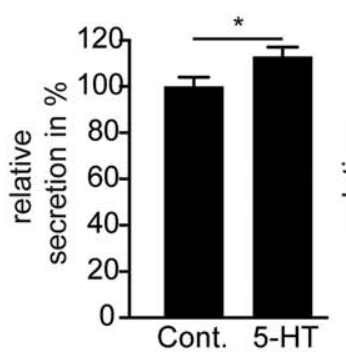

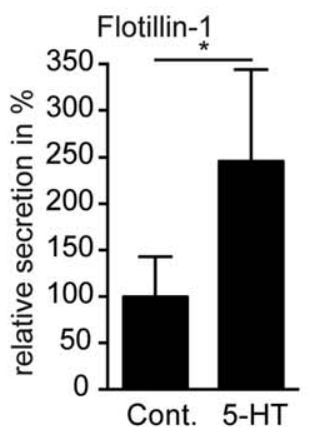

IDE

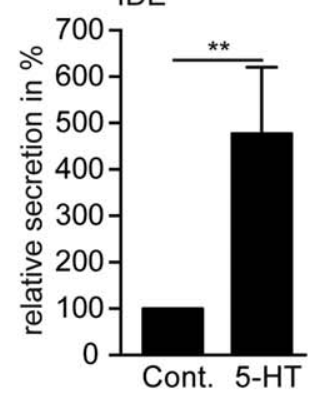

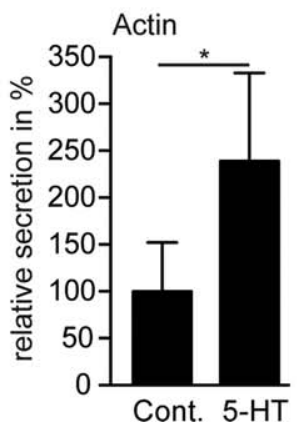

FIGURE 1: 5-HT stimulates secretion of exosomal proteins from microglial cells. A. Cells were incubated in the absence or presence of 5$\mathrm{HT}$ at the indicated concentration $(5,25$, and $50 \mu \mathrm{M})$ and secreted IDE detected by Western immunblotting $(n=3)$. B. MTT reduction assay did not show toxic effects of 5-HT on BV-2 cells at the indicated concentrations and incubation times. C,D. BV-2 cells (C) or primary microglia from mouse brain (D) were incubated in absence or presence of $25 \mu \mathrm{M} 5-\mathrm{HT}$ and the respective proteins secreted into conditioned media detected by immunoblotting $(n=3)$.

GelRed. As positive controls for the RT-PCR procedure, we used genomic DNA of BV-2 cells.

\section{$\mathrm{Ca}^{2+}$ Measurements}

BV-2 cells were pretreated over night in the presence or absence of the indicated antagonists and then bulk labeled with Fluo- 4 by incubation in cell culture medium supplied with Fluo-4 AM (3 $\mu \mathrm{M}$, Invitrogen) and Probenecid (2 mM, Sigma-Aldrich) for 30 min at $37^{\circ} \mathrm{C}$, followed by a 30 -min washing period. Subsequent time-lapse recordings were performed with a Confocal Laserscan Microscope (Leica DMI 6000, SP8, Leica, Mannheim, Germany) at an excitation wavelength of $488 \mathrm{~nm}$ (Haberlandt et al., 2011). Emission was detected between 500 and $650 \mathrm{~nm}$ every $15 \mathrm{~s}$.
Changes in intracellular $\mathrm{Ca}^{2+}$ concentration $\left(\left[\mathrm{Ca}^{2+}\right]_{\mathrm{i}}\right)$, measured as change in fluorescence intensity $(\Delta F)$, were offline normalized to baseline fluorescence $(F 0)$ according to $\Delta F / F 0=(F-F 0) / F 0$. To this end, cell surfaces were fitted for every time point applying particle analysis. Time courses of mean intensities were tracked and ratios calculated for each particle. Only cells with a complete track over the whole time period were plotted. Pre-application base lines were averaged, fitted linearly, and used to correct for bleaching. Three independent experiments were performed for controls and each pharmacological pre-treatment. Data analysis was performed with LAS Live Data Mode (Leica), Imaris (Bitplane, Zurich, Switzerland), and IgorPro 6 software (WaveMetrix, Lake Oswedo, USA). 


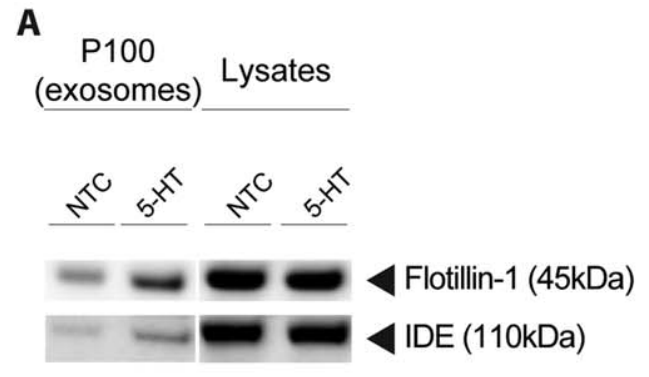

Flotillin-1

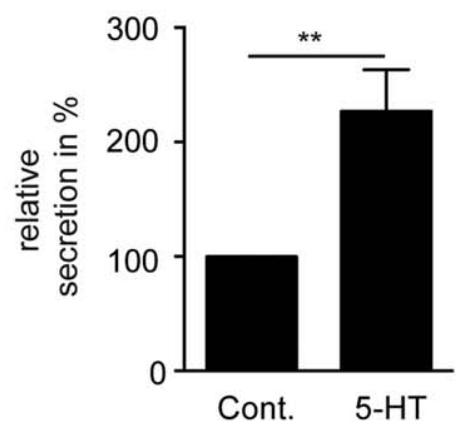

IDE

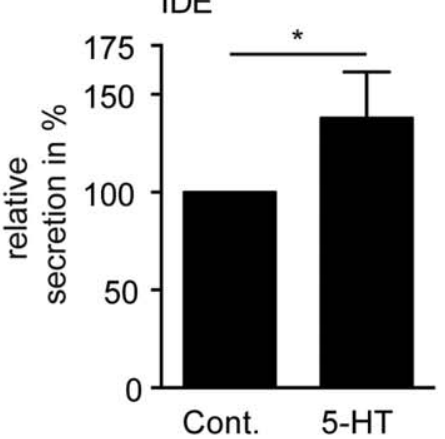

B Cont.

$5-\mathrm{HT}$

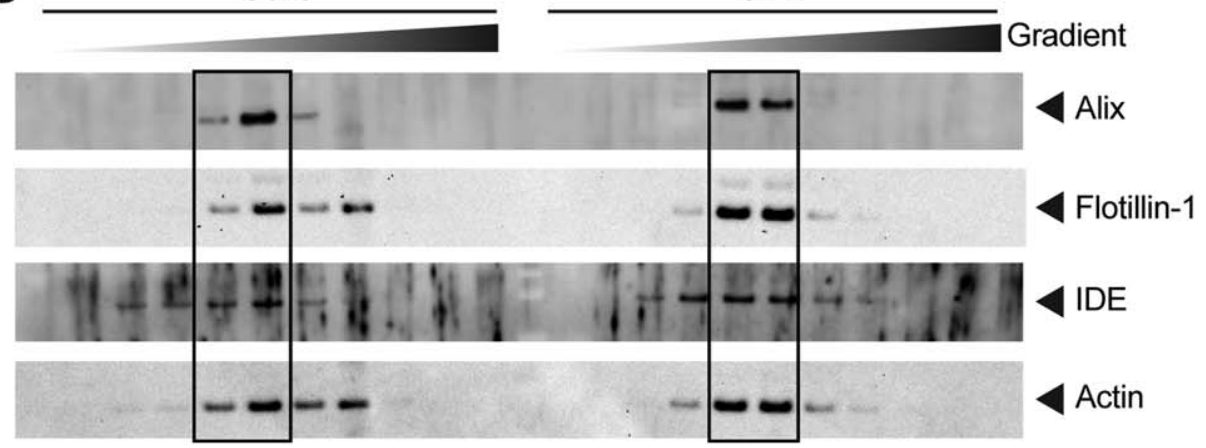

FIGURE 2: 5-HT stimulates release of exosomes. A. Detection and quantification of exosomal proteins in the P100 exosomal fraction upon incubation of BV-2 cells with or without 5-HT. BV-2 cells were incubated in the absence or presence of 5-HT, and conditioned media subjected to a series of centrifugation steps (see Methods, and Tamboli et al., 2010). 5-HT induced an increase in levels of exosome-associated proteins $(n=2)$. B. After differential centrifugation, the P100 pellet was applied to centrifugation on a sucrose gradient. Exosomal proteins were then detected in individual fractions by Western immunoblotting. Alix, flotillin-1, IDE, and actin comigrated, indicating their simultaneous secretion in exosomes.

\section{Co-culture of Microglia with Embryonic Stem Cell- derived 5-HT-ergic Neurons}

Mouse embryonic stem (ES) cell-derived serotonergic neurons were generated as described previously (Lau et al., 2010). Briefly, ES cells were cultured for at least two passages in Dulbecco's modified Eagle's medium supplemented with $15 \% \mathrm{v} / \mathrm{v}$ ES cell-qualified fetal bovine serum (PAA, A15-108), 1x MEM non-essential amino acids, penicillin $\left(100 \mathrm{U} \mathrm{mL}^{-1}\right)$ and streptomycin $\left(100 \mu \mathrm{g} \mathrm{m}^{-1}\right.$; all from Life Technologies) and LIF (1,000 $\mathrm{U} \mathrm{mL}^{-1}$, Millipore). The serotonergic differentiation was induced by removal of LIF and addition of

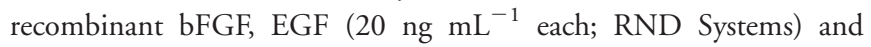
ethanolamine (30 nM, Sigma). For the co-culture experiments, 20,000 ES cell-derived neuronal precursors $/ \mu \mathrm{m}^{2}$ were plated on $0.1 \% \mathrm{v} / \mathrm{v}$ gelatin-coated 24-well dishes and kept in differentiation medium for 7 days to generate stem cell-derived serotonergic neurons. Next, 80,000 BV-2 cells were seeded into the wells with neurons, and $16 \mathrm{~h}$ later conditioned media and cells were harvested and subjected to immunoblotting.

\section{Statistical Analysis}

Statistical analysis was performed with standard statistical functions of Excel or GraphPadPrizm using a two-tailed $t$ test. If not stated otherwise, all values represent means $\pm \mathrm{SD}$; the number of replicates is indi- cated in each figure legend. The error probability was set at $P<0.05$ (indicated in figures by $\left.\left.{ }^{*}\right), P<0.01{ }^{(* *}\right)$ or $P<0.001{ }^{(* *)}$.

\section{Results}

\section{5-HT Stimulates the Release of Exosomes from Primary Microglia and BV-2 Cells}

To assess whether 5-HT affects the release of exosomes, we used an established secretion assay for microglial cells (Glebov et al., 2011; Tamboli et al., 2010). First, we analyzed the effect of 5HT at different concentrations on the release of the insulin degrading enzyme (IDE), a protein known to be released from microglia in association with exosomes. 5-HT increased the release of IDE in a concentration dependent manner (Fig. 1A). At the concentrations tested, 5-HT did not exert toxic effects on microglial BV-2 cells as analyzed by MTT assay (Fig. 1B) (Tamboli et al., 2010). We decided to apply 5-HT at a concentration of $25 \mu \mathrm{M}$ for further experiments. It should be noted that 5 -HT is very instable and thus, is often used at concentrations up to $10 \mathrm{mM}$ in cellular assays (Hambek et al., 2006).

We next assessed the effect of 5-HT on the release of flotillin-1 and actin from BV-2 cells. Both proteins are also associated with exosomes in other cell types. 5-HT significantly 
A

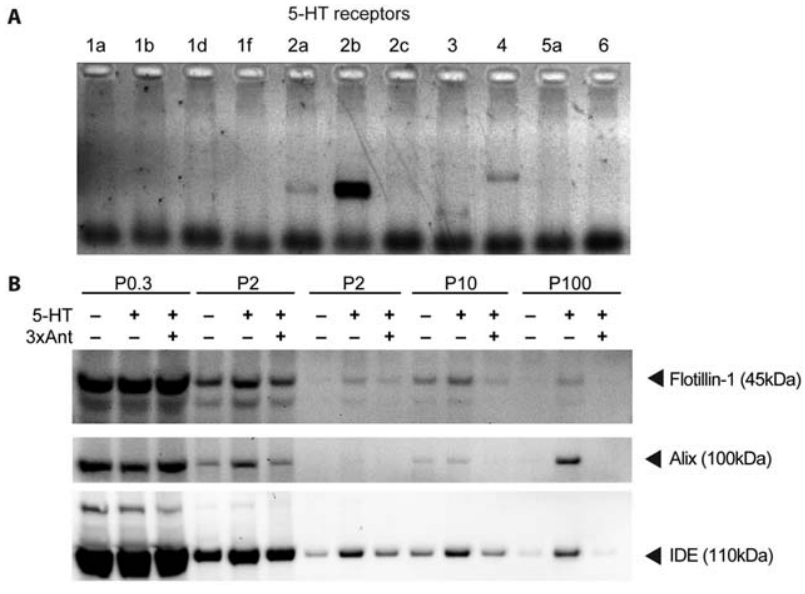

C
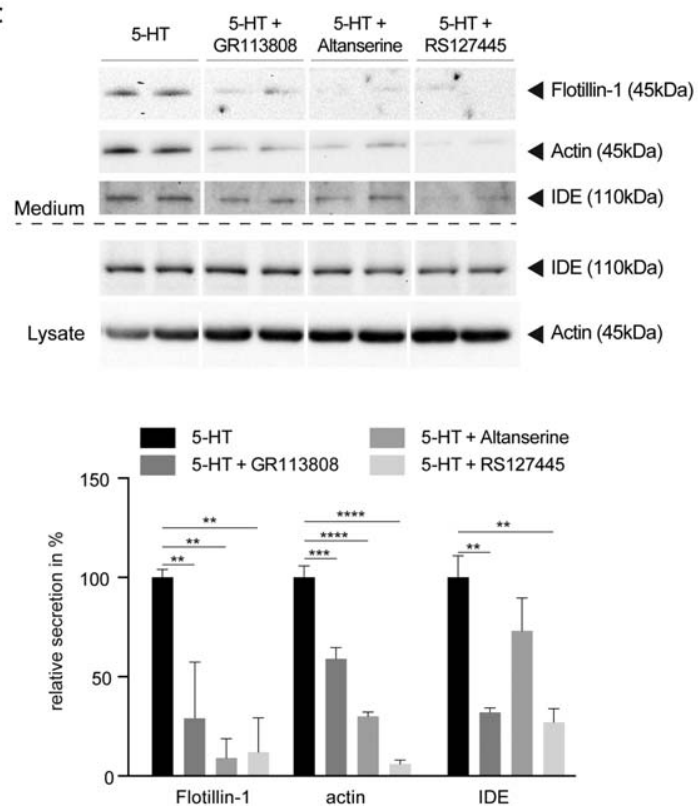

FIGURE 3: Expression and functional involvement of $5-\mathrm{HT}_{2}$ and $5-\mathrm{HT}_{4}$ receptors in microglial exosome release. A. Analysis of 5HTR mRNA expression by RT-PCR. B. Detection of exosomal proteins in the P100 exosomal fraction upon incubation of BV-2 cells in the presence or absence of 5-HT and a combination of specific receptor antagonists GR113808 (against $5-\mathrm{HT}_{4} \mathrm{R}$ ), altanserine (against 5-HT $2 \mathrm{R}$ ), and RS 127445 (against 5-HT $2 \mathrm{~b}$ ). Conditoned media were subjected to differential centrifugation steps and exosomal proteins detected in individual fractions by Western immunoblotting. C. Co-treatment of BV-2 cells with 5-HT and individual specific antagonists. Proteins in conditioned media were detected by Western immunoblotting and quantified by ECL imaging $(n=3)$.

increased the levels of flotillin-1 (246\% $\pm 98 \%$ of control), actin $(239 \% \pm 94 \%$ of control), and IDE $(477 \% \pm 83 \%)$ in conditioned media of microglial BV-2 cells (Fig. 1C).

To confirm that the observed effect was not limited to the microglial BV-2 cell line, we also tested the effect of 5HT on mouse primary microglial cells. As observed for BV-2 cells, 5-HT also increased levels of flotillin-1 (113\% $\pm 4 \%$ of control) and IDE $(178 \% \pm 14 \%$ of control) in conditioned media of primary mouse microglia (Fig. 1D).
To confirm that these proteins are indeed associated with microglia-derived exosomes, we performed biochemical isolation of exosomes by differential centrifugation. IDE was detected together with flotillin-1 in the P100 fraction. Quantification revealed that both proteins are significantly increased in the P100 fraction upon cell incubation with 5-HT (Fig. 2A). In addition, the vesicles in the P100 fractions were further subjected to subsequent fractionation on a sucrose gradient. Importantly, known exosomal marker proteins like alix, flotillin-1, IDE, and actin were found in same fractions. All four proteins were increased in the same exosomal fractions upon cell treatment with 5-HT (Fig. 2B). These data strongly indicate a general stimulation of exosome release from microglia upon treatment with this neurotransmitter.

\section{Functional Involvement of 5-HTRs in the Regulation of Exosome Secretion}

An increase in exosome release upon treatment with 5-HT implicates that microglial cells should express one or more types of 5-HTRs. RT-PCR revealed that BV-2 cells indeed express 5- $\mathrm{HT}_{2 \mathrm{a}}, 5-\mathrm{HT}_{2 \mathrm{~b}}, 5-\mathrm{HT}_{3}$, and 5-HT 4 Rs (Fig. 3A). Recently, a similar expression pattern of 5-HTRs has also been described for primary microglia (Krabbe et al., 2012).

The $5-\mathrm{HT}_{2}$ and $5-\mathrm{HT}_{4}$ receptors belong to the Gprotein coupled receptor superfamily. Pretreatment of the cells with a combination of three antagonists of these receptors, strongly reduced release of exosomes in the P100 fraction as indicated by the reduction in exosome-associated proteins flotillin-1, alix, and IDE (Fig. 3B). The effect of 5-HT was most pronounced in the exosome (P100) fraction as compared with other vesicular (P10) fractions, suggesting a preferential effect on exosome secretion. To further dissect the involvement of different 5-HTRs, we applied the specific receptor antagonists separately. RS127445 and GR113808 that target 5-HT 2 b and $5-\mathrm{HT}_{4} \mathrm{Rs}$, respectively, significantly attenuated the stimulation of exosome release by $5-\mathrm{HT}$. Altanserine that targets $5-\mathrm{HT}_{2 \mathrm{a}} \mathrm{Rs}$, also decreased the 5-HT stimulated exosome release (Fig. 3C). The treatment with 5-HT in combination with receptor antagonists did not affect cell viability as tested by MTT assay (not shown). The differential extent of inhibition by the antagonists might be explained by the different expression levels of 5-HTRs (Fig. 3A). Taken together our data suggests that both $5-\mathrm{HT}_{2}$ and $5-\mathrm{HT}_{4} \mathrm{Rs}$ might be involved in stimulation of exosome release by $5-\mathrm{HT}$.

\section{5-HT Increases Cytosolic $\mathrm{Ca}^{2+}$ to Stimulate Exosome Release}

The $5-\mathrm{HT}_{2} \mathrm{Rs}$ signal via PLC to increase the cytosolic $\mathrm{Ca}^{2+}$ concentration (Pocock and Kettenmann, 2007). To test whether stimulation of PLC can increase exosome release from microglia, we incubated BV-2 cells with $3 \mathrm{~m} 3 \mathrm{FBS}$, a specific activator of PLC. $3 \mathrm{~m} 3 \mathrm{FBS}$ significantly increased 
A
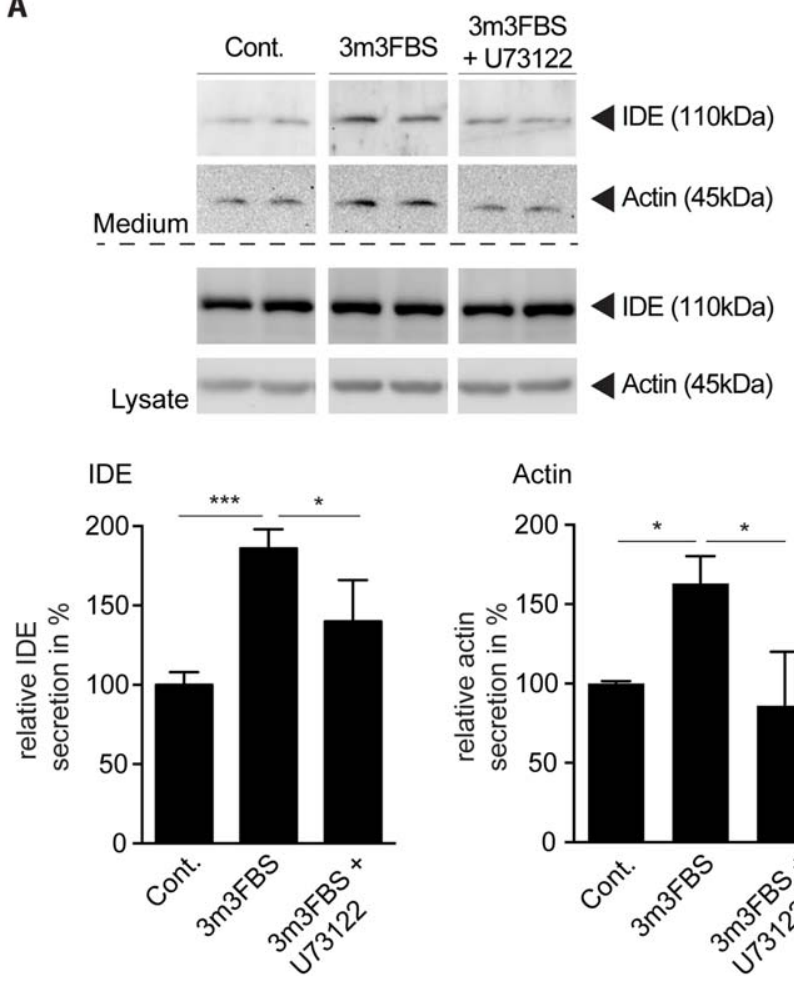

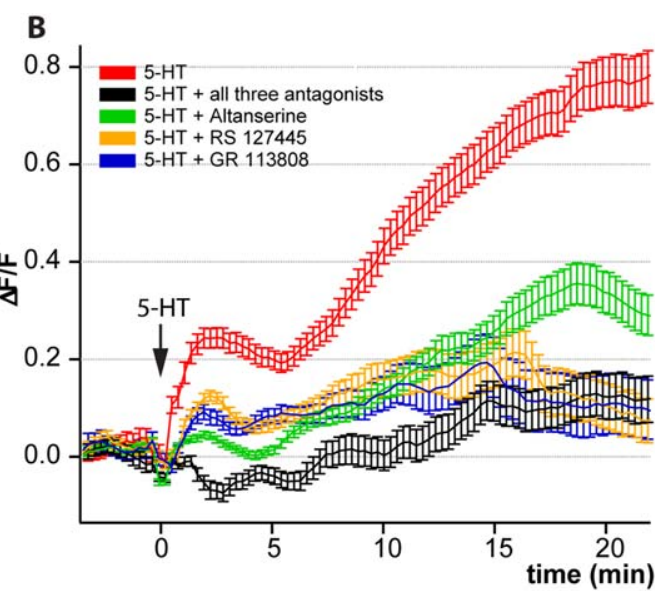

FIGURE 4: Involvement of PLC and $\mathrm{Ca}^{2+}$ in microglial exosome release. A. BV-2 cells were incubated in the absence or presence of the PLC-specific activator 3m3FBS alone or in combination with the specific PLC inhibitor U73122 for $5 \mathrm{~h}$. Proteins in conditioned media and cell lysates were detected by Western immunoblotting and quantifed by ECL imaging $(n=3)$. B. BV-2 cells were bulk loaded with the $\mathrm{Ca}^{2+}$ indicator Fluo-4. Time lapse recordings were performed before and during application of 5-HT (25 $\left.\mu \mathrm{M}\right)$. $\Delta F / F$ ratios were determined for all individual cells with a complete track of mean fluorescence intensities. The $5-\mathrm{HT}$ mediated increase in $\left[\mathrm{Ca}^{2+}\right]_{\mathrm{i}}(\mathrm{no}$ antagonist, $n=236$ ) was decreased by pretreatment with the 5-HT antagonists GR $113808(n=141)$, RS 127445 $(n=289)$, altanserine $(n=410)$. The combination of all three antagonists had the strongest inhibitory effect $(n=210)$. Error bars indicate $95 \%$ confidence intervals. [Color figure can be viewed in the online issue, which is available at wileyonlinelibrary.com.]

exosome release as indicated by elevated levels of IDE and $\beta$-actin in conditioned media (to $186 \% \pm 12 \%$ vs. control, $P=0.0005$ and $163 \% \pm 30 \%$ vs. control, $P=0.0223$, respectively). Importantly, the co-treatment with the selective PLC-inhibitor U73122 attenuated the 3m3FBS-induced secretion of exosomal proteins (Fig. 4A).

Next we analyzed the effect of $5-\mathrm{HT}$ on the $\left[\mathrm{Ca}^{2+}\right]_{\mathrm{i}}$ employing the fluorescent $\mathrm{Ca}^{2+}$ sensor Fluo-4. Application of 5-HT mediated a biphasic increase in $\left[\mathrm{Ca}^{2+}\right]_{i}$. Pretreatment of the cells with individual subtype-specific 5-HTR antagonists significantly reduced the $\left[\mathrm{Ca}^{2+}\right]_{\mathrm{i}}$ increase (Fig. 4B). Simultaneous co-treatment of cells with the three different antagonists almost completely blocked the response to 5-HT. Together, these data indicate that the stimulation of exosome release by 5-HT involves different 5-HTR subtypes and elevation of $\left[\mathrm{Ca}^{2+}\right]_{\mathrm{i}}$.

\section{Involvement of cAMP-GEF1/2 in 5-HT ${ }_{4}$ R Signaling}

The specific 5- $\mathrm{HT}_{4} \mathrm{R}$ antagonist GR113808 also decreased the $\mathrm{Ca}^{2+}$ response and exosome release (see Figs. 3C and $4 \mathrm{~B})$. However, $5-\mathrm{HT}_{4} \mathrm{R}$ signals to adenylate cyclase (AC) via
G $\alpha$ s to stimulate the production of cAMP (Bockaert et al., 2004). To check whether cAMP evokes exosome release, we treated the cells with pertussis toxin (PTX), which increases the intracellular level of cAMP via inhibition of Gai, therefore preventing the inactivation of AC (Burns, 1988). Indeed, treatment of BV-2 cells with PTX strongly induced exosome release as indicated by a approximately sixfold increase of IDE in the conditioned media (Fig. 5A).

Whether $5-\mathrm{HT}_{4} \mathrm{Rs}$ can regulate $\mathrm{Ca}^{2+}$ in microglia via signaling to PLC has not been shown previously. However, cAMP can activate GEF1/2 (epac1/2) (de Rooij et al., 2000), and cAMP-GEF1/2 could signal to PLC via Rap1 (Oestreich et al., 2007). Thus, we hypothesized that $5-\mathrm{HT}_{4} \mathrm{Rs}$ might also be functionally linked to $\mathrm{Ca}^{2+}$ signaling in $\mathrm{BV}-2$ microglia via cAMP-dependent RapGEF (epac1/2). We tested whether direct activation of epac1/2 with 8-CPT (selective activator of epac1/2) recapitulated the 5-HT induced release of exosomes. Indeed, treatment of microglia with 8-CPT increased secretion of exosomes, as indicated by increased levels of flotillin-1, actin, and IDE in conditioned media (Fig. $5 \mathrm{~B})$. Taken together, these findings suggest that stimulation 
A

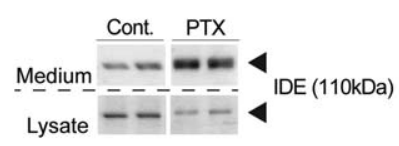

B
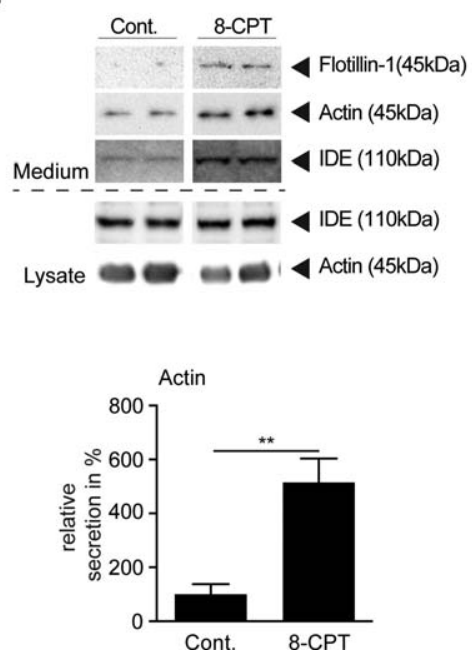
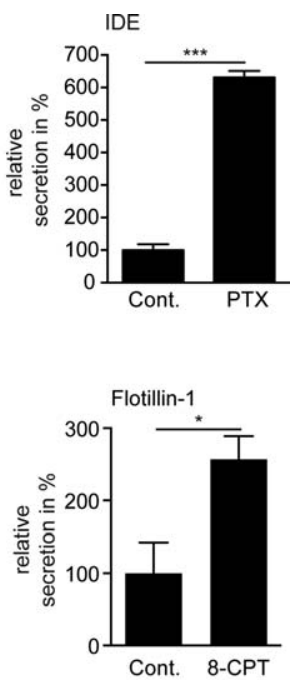

Cont. 8-CPT

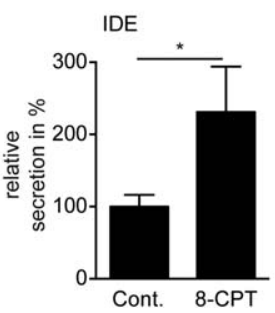

FIGURE 5: Stimulation of exosome release by CAMP and epac1/ 2. A. BV-2 were incubated with or without $1 \mu \mathrm{M}$ PTX (to increase cAMP via inhibition of Gai) for $8 \mathrm{~h}$. IDE in conditioned media and cell lysates was detected by Western immunoblotting. Relative secretion was quantified by $E C L$ imaging $(n=3)$. B. Stimulation of epac1/4 with the specific activator 8-CPT also significantly promoted the release of exosomal proteins $(n=3)$.

of $5-\mathrm{HT}_{4} \mathrm{Rs}$ might increase exosome release via epac1/2/Rap1 signaling to PLC.

\section{Serotonergic Neurons Stimulate Exosome Release from Microglia}

In the brain, 5-HT is produced by a specific subset of neurons (Smidt and van Hooft, 2013). Thus, we wanted to test whether exosome release could be stimulated by serotonergic neurons in a co-culture system. In conditioned media from co-cultures of mouse BV-2 microglial cells and ES cell-derived serotonergic neurons, we observed a significant increase in levels of secreted IDE (to $154.7 \% \pm 1.67 \%$; Fig. $6 \mathrm{~A}$ ) as compared with control cultures with BV-2 cells or neurons alone. Serotonergic neurons alone secreted only marginal levels of IDE, indicating that the secreted IDE mainly derived from BV-2 cells. Importantly, pretreatment of the co-cultures with 5-HTRs antagonists (RS127445, GR113808, and altanserine) significantly reduced this secretion (Fig. 6A), indicating the involvement of 5-HTRs in the neuron-dependent stimulation of microglial exosome release. Together, the combined data suggest that microglia respond to 5-HT released from serotonergic neurons with increased secretion of exosomes.

\section{Discussion}

Here we demonstrate that 5-HT can stimulate the release of exosomes from microglial cells. This effect is mediated by microglial 5-HTRs and involves the elevation of $\left[\mathrm{Ca}^{2+}\right]_{\mathrm{i}}$ levels (Fig. 6B).

Cytosolic $\mathrm{Ca}^{2+}$ is critical in vesicle fusion at synapses (for review: Kochubey et al., 2011) as well as for the fusion of secretory lysosomes with the plasma membrane (Verderio et al., 2011). $\mathrm{Ca}^{2+}$ has also been suggested to modulate exosome release from other cell types, including SH-SY5Y and K562 cells (Emmanouilidou et al., 2010; Savina et al., 2003, 2005).

A

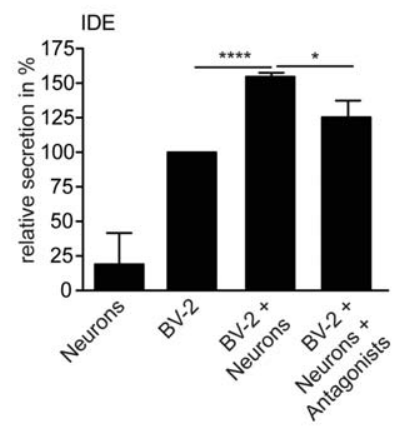

B

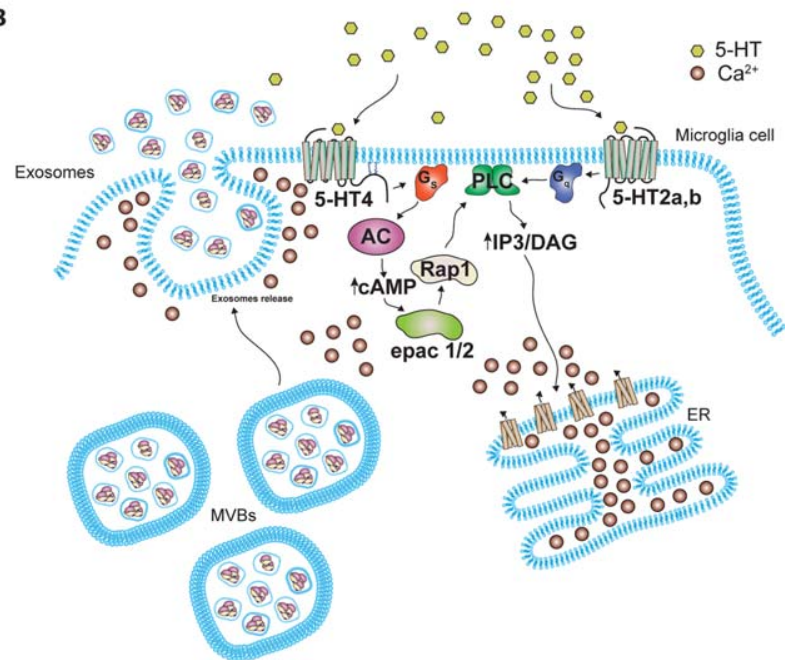

FIGURE 6: ES cell-derived serotonergic neurons stimulate the release of exosomes from BV-2 cells. A. BV-2 cells and ES cellderived serotonergic neurons were cultured separately or together for $12 \mathrm{~h}$ in the presence or absence of the 5-HTR antagonists GR113808, altanserine, and RS 127445. IDE was detected in conditioned media and cell lysates, respectively. Coculture of BV-2 cells with neurons increased levels of secreted IDE. Neurons alone secreted very little if any IDE during the incubation. Pre-treatment of co-cultures with the 5-HTR antagonists significantly reduced the amount of secreted IDE $(n=3)$. B. Suggested signaling pathways that might regulate exosome release from microglial cells upon stimulation with 5-HT. The 5-HT can activate $5-\mathrm{HT}_{2 \mathrm{a}}, 5-\mathrm{HT}_{2 \mathrm{~b}}$, and $5-\mathrm{HT}_{4} \mathrm{Rs}$ thereby activating two distinct pathways that converge on PLC. [Color figure can be viewed in the online issue, which is available at wileyonlinelibrary.com.] 
Our data suggest that PLC-mediated increase in $\left[\mathrm{Ca}^{2+}\right]_{\mathrm{i}}$ upon stimulation of 5-HTRs leads to increased fusion of MVBs with the plasma membrane thereby allowing the release of intraluminal vesicles as exosomes. This notion is supported by the observation that direct elevation of $\left[\mathrm{Ca}^{2+}\right]_{\mathrm{i}}$ by thapsigargin also increased exosome release (not shown).

RT-PCR revealed mRNA expression of different 5HTRs in BV-2 cells, including 5- $\mathrm{HT}_{2 \mathrm{a}}$ and $5-\mathrm{HT}_{2 \mathrm{~b}} \mathrm{Rs}$. $\mathrm{HT}_{2 \mathrm{a}}$

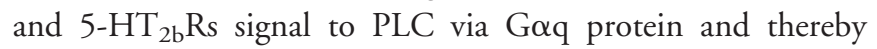
increase $\left[\mathrm{Ca}^{2+}\right]_{\mathrm{i}}$ (Berumen et al., 2012; Cussac et al., 2008; Osborne et al., 1993). We also detected $5-\mathrm{HT}_{4} \mathrm{Rs}$ mRNA in BV-2 cells, and the results with a selective antagonist suggest that this receptor is also involved in the regulation of exosome release. Our data indicate that $5-\mathrm{HT}_{4} \mathrm{R}$, although directly targeting AC, could also cross-talk to PLC via cAMPmediated activation of epac1/2/Rap1 in microglia cells.

It has been shown that in the healthy and diseased brain, neurons directly communicate through neurotransmitters with astrocytes (Seifert et al., 2006; Volterra and Meldolesi, 2005; Volterra and Steinhäuser, 2004). In addition, a recent report demonstrated an effect of glutamatergic neurons on exosome secretion from oligodendrocytes, thereby identifying another type of neurotransmitter dependent neuron-to-glia signaling (Frühbeis et al., 2013). Interestingly, the existence of neuron-microglia signalling has been suggested previously (Pocock and Kettenmann, 2007). Accordingly, 5-HT released from neurons could approach microglial receptors through "volume transmission" or "spillover" of the transmitter to stimulate exosome release from microglia. Our results obtained with a co-culture model using ES cell-derived serotonergic neurons and microglial BV-2 cells are compatible with such a scenario. This is, to our knowledge, the first experimental finding that neuron-derived $5-\mathrm{HT}$ indeed can stimulate release of exosomes from microglial cells. On the basis of our results we conclude that 5-HT stimulates preferentially the release of exosomes, rather than that of other extracellular vesicles. However, it will be interesting to further dissect the effect of 5-HT on the release and protein composition of the different pools of extracellular vesicles (for review: Raposo and Stoorvogel, 2013).

At this time it can only be speculated about the physiological or pathophysiological relevance of the present findings. Microglial cells secrete neurotrophic factors such as BDNF, IGF-1, or glial cell line-derived neurotrophic factor and also shape neuronal architecture (Batchelor et al., 1999; Miwa et al., 1997; Nakajima and Kohsaka, 2004). The proteomic analysis of exosomes also revealed the presence of inflammatory modulators or neurotrophic factors, suggesting that glial cells use unconventional pathways for protein secretion (www. exocarta.org) (Mathivanan et al., 2012).
Recent experimental data obtained with a mouse model of Alzheimer's disease demonstrated that increased 5-HT levels were associated with reduced concentrations of amyloid $\beta$ peptides $(A \beta)$ in brain interstitial fluid and decreased $A \beta$ plaque burden (Cirrito et al., 2011). Because increased 5-HT concentrations were also associated with elevated activity of $\alpha$-secretase and transcriptional changes of certain $\gamma$-secretase components, it was speculated that 5-HT might affect the generation of $A \beta$. As exosome-associated IDE from microglial cells has been shown to promote degradation of extracellular $A \beta$ in vitro (Glebov and Walter, 2011; Tamboli et al., 2010), it is intriguing to speculate that the beneficial effects of 5-HT in lowering $A \beta$ load in vivo, also involves stimulated exosome release. Together, the demonstration of neurotransmitter dependent release of exosomes from microglia should stimulate further studies on the molecular mechanisms and the physiological and pathophysiological relevance of neuronal signaling to microglia.

\section{Acknowledgment}

Grant sponsor: Junior Principal Investigator Grant of Bonn University; Grant number: BONFOR O-129.0100; Grant sponsor: DFG; Grant numbers: KFO177, WA1477/42, SFB645, SFB636, STE 552/3; Grant sponsor: EC Grant (EuroEPINOMICS). ML is supported by the FAZITStiftung.

\section{References}

Batchelor PE, Liberatore GT, Wong JY, Porritt MJ, Frerichs F, Donnan GA, Howells DW. 1999. Activated macrophages and microglia induce dopaminergic sprouting in the injured striatum and express brain-derived neurotrophic factor and glial cell line-derived neurotrophic factor. J Neurosci 19:1708-1716.

Berumen LC, Rodriguez A, Miledi R, Garcia-Alcocer G. 2012. Serotonin receptors in hippocampus. Scientific World J 2012:823493.

Bianco F, Pravettoni E, Colombo A, Schenk U, Moller T, Matteoli M, Verderio C. 2005. Astrocyte-derived ATP induces vesicle shedding and IL-1 beta release from microglia. J Immunol 174:7268-7277.

Bockaert J, Claeysen S, Compan V, Dumuis A. 2004. 5-HT4 receptors. Curr Drug Targets CNS Neurol Disord 3:39-51.

Burns DL. 1988. Subunit structure and enzymic activity of pertussis toxin. Microbiol Sci 5:285-287.

Cirrito JR, Disabato BM, Restivo JL, Verges DK, Goebel WD, Sathyan A, Hayreh D, D’Angelo G, Benzinger T, Yoon H, Kim J, Morris JC, Mintun MA, Sheline YI. 2011. Serotonin signaling is associated with lower amyloid-beta levels and plaques in transgenic mice and humans. Proc Natl Acad Sci USA 108:1496814973.

Cussac D, Boutet-Robinet E, Ailhaud MC, Newman-Tancredi A, Martel JC, Danty N, Rauly-Lestienne I. 2008. Agonist-directed trafficking of signalling at serotonin 5-HT2A, 5-HT2B and 5-HT2C-VSV receptors mediated Gq/11 activation and calcium mobilisation in CHO cells. Eur J Pharmacol 594:32-38.

de Rooij J, Rehmann H, van Triest M, Cool RH, Wittinghofer A, Bos JL. 2000. Mechanism of regulation of the Epac family of cAMP-dependent RapGEFs. $\mathrm{J}$ Biol Chem 275:20829-20836.

Emmanouilidou E, Melachroinou K, Roumeliotis T, Garbis SD, Ntzouni M, Margaritis LH, Stefanis L, Vekrellis K. 2010. Cell-produced alpha-synuclein is 
secreted in a calcium-dependent manner by exosomes and impacts neuronal survival. J Neurosci 30:6838-6851.

Frühbeis C, Frohlich D, Kuo WP, Amphornrat J, Thilemann S, Saab AS, Kirchhoff F, Mobius W, Goebbels S, Nave KA, Schneider A, Simons M, Klugmann M, Trotter J, Kramer-Albers EM. 2013. Neurotransmitter-triggered transfer of exosomes mediates oligodendrocyte-neuron communication. PLoS Biol 11:e1001604.

Glebov K, Schütze S, Walter J. 2011. Functional relevance of a novel SlyX motif in non-conventional secretion of insulin-degrading enzyme. J Biol Chem 286:22711-22715.

Glebov K, Walter J. 2011. Statins in unconventional secretion of insulindegrading enzyme and degradation of the amyloid-beta peptide. Neurodegener Dis 10:309-312.

Haberlandt C, Derouiche A, Wyczynski A, Haseleu J, Pohle J, Karram K, Trotter J, Seifert G, Frotscher M, Steinhäuser C, Jabs R. 2011. Gray matter NG2 cells display multiple $\mathrm{Ca} 2+$-signaling pathways and highly motile processes. PLoS One 6:e17575.

Hambek M, Werner C, Baghi M, Gstottner W, Knecht R. 2006. Prestimulation of head and neck cancer cells with growth factors enhances treatment efficacy. Anticancer Res 26:1091-1095.

Keller S, Ridinger J, Rupp AK, Janssen JW, Altevogt P. 2011. Body fluid derived exosomes as a novel template for clinical diagnostics. J Transl Med 9:86.

Kettenmann H, Hanisch UK, Noda M, Verkhratsky A. 2011. Physiology of microglia. Physiol Rev 91:461-553.

Kochubey O, Lou X, Schneggenburger R. 2011. Regulation of transmitter release by $\mathrm{Ca}(2+)$ and synaptotagmin: Insights from a large CNS synapse. Trends Neurosci 34:237-246.

Krabbe G, Matyash V, Pannasch U, Mamer L, Boddeke HW, Kettenmann H. 2012. Activation of serotonin receptors promotes microglial injury-induced motility but attenuates phagocytic activity. Brain Behav Immunol 26:419-428.

Lau T, Schneidt T, Heimann F, Gundelfinger ED, Schloss P. 2010. Somatodendritic serotonin release and re-uptake in mouse embryonic stem cellderived serotonergic neurons. Neurochem Int 57:969-978.

Mathivanan S, Fahner CJ, Reid GE, Simpson RJ. 2012. ExoCarta 2012: Database of exosomal proteins, RNA and lipids. Nucleic Acids Res 40:1241-1244.

Miwa T, Furukawa S, Nakajima K, Furukawa Y, Kohsaka S. 1997. Lipopolysaccharide enhances synthesis of brain-derived neurotrophic factor in cultured rat microglia. J Neurosci Res 50:1023-1029.

Mohammad-Zadeh LF, Moses L, Gwaltney-Brant SM. 2008. Serotonin: A review. J Vet Pharmacol Ther 31:187-199.

Nakajima K, Kohsaka S. 2004. Microglia: Neuroprotective and neurotrophic cells in the central nervous system. Curr Drug Targets Cardiovasc Haematol Disord 4:65-84.

Oestreich EA, Wang H, Malik S, Kaproth-Joslin KA, Blaxall BC, Kelley GG, Dirksen RT, Smrcka AV. 2007. Epac-mediated activation of phospholipase $\mathrm{C}($ epsilon) plays a critical role in beta-adrenergic receptor-dependent enhancement of Ca2+ mobilization in cardiac myocytes. J Biol Chem 282:5488-5495.
Osborne NN, Fitzgibbon F, Nash M, Liu NP, Leslie R, Cholewinski A. 1993. Serotonergic, 5-HT2, receptor-mediated phosphoinositide turnover and mobilization of calcium in cultured rat retinal pigment epithelium cells. Vis Res 33:2171-2179.

Pocock JM, Kettenmann H. 2007. Neurotransmitter receptors on microglia. Trends Neurosci 30:527-535.

Prada I, Furlan R, Matteoli M, Verderio C. 2013. Classical and unconventional pathways of vesicular release in microglia. Glia 61:1003-1017.

Raposo G, Stoorvogel W. 2013. Extracellular vesicles: Exosomes, microvesicles, and friends. J Cell Biol 200:373-383

Savina A, Fader CM, Damiani MT, Colombo MI. 2005. Rab11 promotes docking and fusion of multivesicular bodies in a calcium-dependent manner. Traffic 6:131-143.

Savina A, Furlan M, Vidal M, Colombo MI. 2003. Exosome release is regulated by a calcium-dependent mechanism in K562 cells. J Biol Chem 278: 20083-20090.

Seifert G, Schilling K, Steinhauser C. 2006. Astrocyte dysfunction in neurological disorders: A molecular perspective. Nat Rev Neurosci 7:194-206.

Simons M, Raposo G. 2009. Exosomes-Vesicular carriers for intercellular communication. Curr Opin Cell Biol 21:575-581.

Simpson RJ, Lim JW, Moritz RL, Mathivanan S. 2009. Exosomes: Proteomic insights and diagnostic potential. Expert Rev Proteomics 6:267-283.

Smidt MP, van Hooft JA. 2013. Subset specification of central serotonergic neurons. Front Cell Neurosci 7:200.

Street JM, Barran PE, Mackay CL, Weidt S, Balmforth C, Walsh TS, Chalmers RT, Webb DJ, Dear JW. 2012. Identification and proteomic profiling of exosomes in human cerebrospinal fluid. J Transl Med 10:5.

Streit WJ. 2002. Microglia as neuroprotective, immunocompetent cells of the CNS. Glia 40:133-139.

Tamboli IY, Barth E, Christian L, Siepmann M, Kumar S, Singh S, Tolksdorf K, Heneka MT, Lutjohann D, Wunderlich P, Walter J. 2010a. Statins promote the degradation of extracellular amyloid \{beta\}-peptide by microglia via stimulation of exosome-associated insulin-degrading enzyme (IDE) secretion. J Biol Chem 285:37405-37414.

Turola E, Furlan R, Bianco F, Matteoli M, Verderio C. 2012. Microglial microvesicle secretion and intercellular signaling. Front Physiol 3:149.

van Niel G, Porto-Carreiro I, Simoes S, Raposo G. 2006. Exosomes: A common pathway for a specialized function. J Biochem 140:13-21.

Verderio C, Cagnoli C, Bergami M, Francolini M, Schenk U, Colombo A, Riganti L, Frassoni C, Zuccaro E, Danglot L, Wilhelm C, Galli T, Canossa M, Matteoli M. 2011. TI-VAMP/VAMP7 is the snare of secretory lysosomes contributing to ATP secretion from astrocytes. Biol Cell 104:213-228.

Volterra A, Meldolesi J. 2005. Astrocytes, from brain glue to communication elements: The revolution continues. Nat Rev Neurosci 6:626-640.

Volterra A, Steinhauser C. 2004. Glial modulation of synaptic transmission in the hippocampus. Glia 47:249-257. 